\title{
Identifying social participation subgroups of individuals with severe mental illnesses: a latent class analysis
}

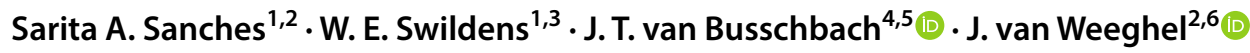

Received: 24 October 2018 / Accepted: 26 March 2019/ Published online: 25 May 2019

(c) The Author(s) 2019

\begin{abstract}
Purpose To investigate factors that influence participation in and needs for work and other daytime activities among individuals with severe mental illnesses (SMI).

Methods A latent class analysis using routine outcome monitoring data from 1069 patients was conducted to investigate whether subgroups of individuals with SMI can be distinguished based on participation in work or other daytime activities, needs for care in these areas, and the differences between these subgroups.

Results Four subgroups could be distinguished: (1) an inactive group without daytime activities or paid employment and many needs for care in these areas; (2) a moderately active group with some daytime activities, no paid employment, and few needs for care; (3) an active group with more daytime activities, no paid employment, and mainly met needs for care; and (4) a group engaged in paid employment without needs for care in this area. Groups differed significantly from each other in age, duration in MHC, living situation, educational level, having a life partner or not, needs for care regarding social contacts, quality of life, psychosocial functioning, and psychiatric symptoms. Differences were not found for clinical diagnosis or gender. Conclusions Among individuals with SMI, different subgroups can be distinguished based on employment situation, daytime activities, and needs for care in these areas. Subgroups differ from each other on patient characteristics and each subgroup poses specific challenges, underlining the need for tailored rehabilitation interventions. Special attention is needed for individuals who are involuntarily inactive, with severe psychiatric symptoms and problems in psychosocial functioning.
\end{abstract}

Keywords Latent class analysis - Severe mental illnesses - Social participation · Paid employment and daytime activities · Routine outcome monitoring

Sarita A. Sanches

s.a.sanches@uvt.nl

1 Altrecht Institute for Mental Health Care, Lange Nieuwstraat 119, 3512 PG Utrecht, The Netherlands

2 Tilburg School of Social and Behavioral Sciences, Tranzo Scientific Center for Care and Welfare, Tilburg University, Tilburg, The Netherlands

3 Inholland University of Applied Sciences, De Boelelaan 1109, 1081 HV Amsterdam, The Netherlands

4 University of Groningen, University Medical Center Groningen, University Center for Psychiatry, Groningen, The Netherlands

5 Department of Movement and Education, Windesheim University of Applied Sciences, Zwolle, The Netherlands

6 Phrenos Center of Expertise, Utrecht, The Netherlands

\section{Introduction}

Social participation, defined as engaging in paid or unpaid employment and other daytime activities such as education, is an important facilitator of recovery for individuals with severe mental illnesses (SMI) [1]. It seems to be linked to better self-esteem, enhanced feelings of self-efficacy, less severe symptoms [2-4], and a higher quality of life for individuals with SMI as well as those in the general population [5-8]. Paid employment is particularly valued, as it promotes financial independence, societal recognition, structure, and identity while providing coping strategies for psychiatric problems [4, 9-11]. It also promotes social inclusion and is associated with higher empowerment, better recovery, and a lower number of unmet needs for care [12, 13]. In fact, paid employment and other daytime activities are an important part of many definitions of recovery $[14,15]$. 
Considering these benefits, it is not surprising that most individuals with SMI express a wish to engage in employment and other daytime activities, with numbers generally ranging from 50 to $60 \%$ [16-18], but as high as 97\% [19].

These numbers sharply contrast with the fact that many individuals with SMI face problems when participating in work or other activities [14, 20]. Unemployment rates for this group range from 65 to $93 \%$ [21-23], whereas these rates hover around $5 \%$ for the general population in western countries [24-26]. Problems with participation are not limited to employment. Global studies show that individuals with SMI also spend little time on education or other activities. Rather, a large portion of their time is spent on passive activities such as sleeping, sitting, and watching TV or their surroundings [9, 27-32], which seem to have detrimental consequences for physical health, promote boredom, and lead to underuse of capacities [33-35].

The discrepancy between the large majority of individuals with SMI who desire to engage in employment and other daytime activities and those who actually engage is caused by factors such as stigmatization by society and potential employers, lack of experience and education, fear of losing financial benefits, psychiatric symptoms, and cognitive impairments [36-39]. Self-stigmatization and anticipated discrimination also discourage individuals with SMI to engage in work or other meaningful daytime activities (the 'why try' effect [40, 41]).

Although evidence-based vocational rehabilitation approaches have been developed in the past years, access to these services remains limited [23], a phenomenon known as the science to service gap [42]. In consequence, many individuals with SMI experience unmet needs for care regarding social participation [43-45]. To overcome these barriers, it is important to understand which patientrelated factors influence whether individuals with SMI participate in work and other daytime activities or not, and to gain insight into the extent to which these individuals' social participation needs are addressed by mental health care (MHC).

Age, educational level, work history, psychotic symptoms, social functioning, and cognitive impairments are identified factors related to the level of social participation $[22,36,46,47]$. However, since most research in this area is based on small samples of clients of vocational services, generalization is difficult and can lead to contradictory results [48].

This study investigates characteristics related to social participation from a large representative sample of individuals with SMI using data gathered through routine outcome monitoring (ROM). The first aim is to explore whether subgroups of individuals with SMI can be distinguished based on their actual level of participation and expressed needs for support in this area. A second aim is to analyze differences between subgroups with regard to psychiatric symptoms, quality of life, and sociodemographic factors.

By describing the different groups based on participation in and expressed needs for work or other activities, we hope to help MHC practitioners in better supporting individuals with SMI to overcome barriers and tailor rehabilitation services to the needs of specific subgroups.

\section{Methods}

\section{Procedure}

Data were obtained through ROM, the routine assessment of patients at regular intervals during treatment [49]. ROM has been implemented in various countries such as the UK, Australia, New Zealand, and The Netherlands [50]. Its main goal is to monitor patients' progress and measure clinically significant change over time [49, 51, 52]. Routine assessments were gathered through interviews by trained psychologists. Patients' informed consent was obtained for scientific use of the data. This procedure was approved by the scientific board of the participating regional MHC center.

\section{Study population}

The study population consisted of patients between 18 and 65 who received care from 12 Flexible Assertive Community Treatment (FACT) teams [53] at a MHC center in a predominantly urban area in the center of The Netherlands. These teams serve 2176 individuals with SMI. The FACT model was developed in The Netherlands and contains all elements of the renowned Assertive Community Treatment (ACT) model [54], one difference being that FACT also targets patients who function in a more or less stable manner. Participating FACT teams consisted of a psychiatrist, psychologist, experience expert, case managers and mental health nurses, and closely collaborated with experts delivering supported employment and supported housing. They provide medical, psychiatric, social, financial, and vocational support which can be intensified according to patients' needs [55]. All teams showed good fidelity [56] and were certified by the Dutch Centre for Certification ACT and Flexible ACT (CCAF; http://www.ccaf.nl). All patients had SMI, indicated by service contact of more than 2 years, a psychiatric diagnosis according to DSM-IV and disabilities in functioning on several life domains [57]. Patients were selected who completed their last ROM measurement in 2012-2017 and had less than 20\% missing information. In total, 1069 patients matched the inclusion criteria. 


\section{Measurements}

Instruments used for ROM with individuals with SMI have to be short, valid, reliable, measure multiple domains, measure from the patients' viewpoint and be used in international research $[51,58]$. For this study, the following measures were selected.

The actual level of social participation was obtained through patient reports on the present hours worked in paid and unpaid employment.

Needs for care in the areas paid work, daytime activities, and social contacts were measured with three items of the extended 25-item research version of the Camberwell Assessment of Need Short Appraisal Schedule (CANSAS) [59, 60]: items 5 (needs concerning daytime activities), 23 (needs concerning paid work), and 14 (needs concerning social contacts). Response options were: $0=$ no problem (no need for care in this area); $1=$ no/moderate problem because of continuing intervention (met need); $2=$ current serious problem (unmet need). The CANSAS shows a moderate to high interrater reliability [61].

Quality of Life (QOL) was measured with the total score on the 12 subjective items of the Manchester Short Assessment of quality of life (MANSA) [62, 63]. These are scored by the patient on a seven-point Likert scale ranging from $1=$ could not be worse to $7=$ could not be better. Total scores range from 0 to 84 . Internal consistency is adequate $(\alpha=0.81$; [64]).

Clinical and social functioning was measured with the Health of the Nation Outcome Scales (HoNOS) [65]. The 12 items that make up 4 subscales (behavioral problems, impairments, symptoms and social problems) were scored by the MHC practitioner on a five-point Likert scale that runs from 0 (no problems) to 4 (very severe problems). Total scores range from 0 to 48 , with higher scores indicating poorer functioning. Both the total and separate symptoms subscale (items on psychotic hallucinations and delusions, depressed mood and other mental, and behavioral problems) were used. HoNOS was found to have good reliability with intra-class correlations above 0.71 [65].

\section{Data analysis}

Latent class analysis (LCA) was used to identify subgroups of individuals with SMI based on their level of social participation. LCA posits that class membership based on an underlying unobserved variable (here: social participation) can be inferred from a set of measured variables. Instead of assigning individuals to classes, a probabilistic approach is used to determine class membership in which the uncertainty of belonging to a certain class is taken into account [66]. Classes were determined based on paid work (yes/no), unpaid work (yes/no), and needs for care regarding paid work and daytime activities (CANSAS items 5 and 23) using LatentGold version 5.0 [67, 68]. Initially, a model was tested with one class, which presumes that there is no relation between indicator variables. Then, the number of classes was gradually increased. The model with the most suitable number of classes was chosen based on the lowest values of the Bayesian Information Criterion (BIC) and Aikaike Information Criterion (AIC3). According to Bozdogan [69], the AIC3 is particularly suited for categorical variables. Model choice was also based on bivariate residuals, which should be $<3$, because values $>3$ suggest possible correlations between indicator variables, a classification error not exceeding $10 \%$, entropy $\mathrm{R}^{2}$ with higher scores representing better-fitting models and a non-significant $p$ value for the goodness-of-fit statistic [70].

To test whether the subgroups differed with regard to sociodemographic characteristics, psychosocial functioning, psychiatric symptoms, and QOL, analyses were conducted using 'Step 3' in Latent Gold. This enables correction of the classification errors and uses the Wald-F statistic to determine significance. Two separate analyses were conducted for, respectively, the continuous outcomes age, duration in MHC, psychosocial functioning, symptoms, and QOL and the categorical outcomes clinical diagnosis (psychosis: yes/ no), living situation (living independently vs. in sheltered accommodation or hospitalized), educational level, and needs for care regarding social contacts. Vignettes will be used to describe the four classes.

\section{Results}

Mean age of the total sample was 44.06 years and mean duration in MHC 16.57 years. Most participants were male (65.5\%) and many participants had a psychotic disorder (76.8\%). Most individuals lived independently (79.3\%) and had a lower educational level $(42.2 \%)$ as opposed to a medium (35\%) or higher educational level (22.8\%) [71]. Approximately $16.2 \%$ of participants were engaged in paid and $29.5 \%$ in unpaid employment. More than half of participants did not report needs for care regarding daytime activities (58.7\%), 24.7\% reported met needs for care and $16.6 \%$ reported unmet needs for care regarding daytime activities. Most participants did not have needs for care regarding paid employment (65.9\%), for $14.1 \%$ these needs were unmet, for $20 \%$ these were met.

\section{Results of the LCA}

Models with 1-6 classes were compared (Table 1). The model with 4 classes was chosen as the best model because it had the best fit based on AIC3, Entropy $R^{2}$ and goodness-of-fit statistic, all bivariate residuals were below $<3$ 
Table 1 Fit statistics latent class analysis

\begin{tabular}{llllllll}
\hline Classes & LL & BIC & AIC3 & Entropy $R^{2}$ & Class error & $\chi^{2}$ & $p$ \\
\hline 1 & -3030.4834 & 6102.8137 & 6078.9669 & 1 & 0 & 423.498 & 0.000 \\
2 & -2956.3182 & 6003.3046 & 5951.6364 & 0.4710 & 0.1361 & 237.065 & 0.000 \\
3 & -2907.8203 & $5955.1302^{\mathrm{a}}$ & 5875.6406 & 0.5736 & 0.1764 & 134.358 & 0.001 \\
$4^{\mathrm{b}}$ & -2888.6732 & 5965.6574 & $5858.3465^{\mathrm{a}}$ & $0.6228^{\mathrm{a}}$ & 0.161 & 87.418 & 0.27 \\
5 & -2880.8509 & 5998.8341 & 5863.7018 & 0.5792 & 0.21 & 71.969 & 0.51 \\
6 & -2877.2824 & 6040.5184 & 5877.5647 & 0.5402 & 0.2645 & 65.077 & 0.51 \\
\hline
\end{tabular}

${ }^{a}$ Best fitting model according to criterion

${ }^{\mathrm{b}}$ Chosen model and the classification error was 0.161 , which is acceptable. In addition, the 4-cluster model resulted in distinct and clinically meaningful classes. The model with three classes had a better fit according to the BIC value, but this model had bivariate residuals $>3$, a lower Entropy $R^{2,}$ and a larger classification error than model 4.

\section{Description of classes}

Descriptive variables for the total sample and per class are displayed in Table 2.

Class 1 (42.6\% of participants) contains almost no individuals with paid employment (1\%). However, 32.3\% of class members were engaged in unpaid employment (Table 2). Most members of class 1 did not express needs for care concerning paid employment (94\%) or daytime activities (76\%). Individuals belonging to class 1 were labeled as moderately active without needs (Fig. 1).

Class 2 (21.5\% of participants) contains individuals who most often did not have paid employment (3.5\% employed). However, the majority was active in unpaid employment (60.4\%). Members of class 2 most often had fulfilled needs for care in the area of paid work and no or fulfilled needs for care regarding daytime activities. These individuals were labeled as active with fulfilled needs.

Class $3(20.9 \%)$ contains individuals that were predominantly not engaged in paid $(90.6 \%)$ or unpaid employment $(90.2 \%)$. Class 3 can be further characterized by having unfulfilled or no needs for care regarding paid employment and a high percentage of unfulfilled needs concerning daytime activities. These individuals were labeled as involuntarily inactive.

Class 4 (14.9\% of participants) is characterized by having paid employment (86.9\%) and almost no unpaid employment (4.4\%). Members of class 4 mostly did not have needs for care regarding paid work or daytime activities $(88 \%)$ and were labeled as active in paid employment.

\section{Differences between classes}

Differences between the classes with regard to sociodemographic characteristics, QOL, psychosocial functioning, and psychiatric symptoms are listed in Table 2. Members of the four classes significantly differed in age, duration in MHC, psychiatric symptoms, psychosocial functioning, living situation, educational level, having a life partner, needs regarding social contacts and QOL, but not in clinical diagnosis or gender.

Members of class 1, moderately active without needs, were on average older and had a longer duration in MHC than the other classes. They had few needs for care regarding social contacts. In addition, they had the fewest psychiatric symptoms and highest QOL after individuals with paid employment. Psychosocial functioning was poorer and educational level was lower than that of the paid employment and active with fulfilled needs classes but better than the involuntarily inactive class.

Members of class 2, active with fulfilled needs, were on average younger, more often living in sheltered housing or hospitalized and had more met needs for care regarding social contacts than members of the other classes. They least often had a life partner. Psychosocial functioning in this group was better than that of moderately active without needs and involuntarily inactive individuals, but poorer than that of individuals with paid employment. They had fewer psychiatric symptoms than involuntarily inactive individuals, but more than the other two classes.

Members of class 3, involuntarily inactive individuals, had the lowest educational level, most unmet needs for care regarding social contacts ( $57.1 \%$ unmet needs), lowest QOL, poorest psychosocial functioning, and the most psychiatric symptoms of all classes. However, involuntarily inactive individuals more often had a life partner than moderately active without needs or active with fulfilled needs individuals. Furthermore, they were comparable 
Table 2 Descriptive variables for the total sample and per class $(N=1069)$

\begin{tabular}{|c|c|c|c|c|c|c|c|}
\hline Variable & $\begin{array}{l}\text { Total sample } \\
(N=1069)\end{array}$ & $\begin{array}{l}\text { Class } 1 \\
\text { Moderately active } \\
\text { without needs } \\
(N=455)\end{array}$ & $\begin{array}{l}\text { Class } 2 \\
\text { Active with } \\
\text { fulfilled needs } \\
(N=230)\end{array}$ & $\begin{array}{l}\text { Class } 3 \\
\text { Involuntarily inactive } \\
(N=224)\end{array}$ & $\begin{array}{l}\text { Class } 4 \\
\text { Paid employment } \\
(N=160)\end{array}$ & Wald $F$ & $p$ \\
\hline & $N(\%)$ & $N(\%)$ & $N(\%)$ & $N(\%)$ & $N(\%)$ & & \\
\hline \multicolumn{8}{|l|}{ Daytime activities } \\
\hline Paid employment & & & & & & 5.667 & 0.13 \\
\hline Yes & $173(16.2)$ & $5(1.1)$ & $8(3.5)$ & $21(9.4)$ & $139(86.9)$ & & \\
\hline No & $896(83.8)$ & $450(98.9)$ & $222(96.5)$ & 203 (90.6) & $21(13.1)$ & & \\
\hline Unpaid employment & & & & & & 48.419 & $0.00^{*}$ \\
\hline Yes & $315(29.5)$ & $147(32.3)$ & $139(60.4)$ & $22(9.8)$ & $7(4.4)$ & & \\
\hline No & $754(70.5)$ & $308(67.7)$ & $91(39.6)$ & $202(90.2)$ & 153 (95.6) & & \\
\hline $\begin{array}{l}\text { Needs for care on daytime activity } \\
\text { (CANSAS item 5) }\end{array}$ & & & & & & 63.881 & $0.00 *$ \\
\hline No needs & $627(58.7)$ & $347(76.3)$ & $87(37.8)$ & $52(23.2)$ & $141(88.0)$ & & \\
\hline Met needs & $264(24.7)$ & $102(22.4)$ & $121(52.6)$ & $22(9.8)$ & $19(12.0)$ & & \\
\hline Unmet needs & $178(16.6)$ & $6(1.3)$ & $22(9.6)$ & $150(67.0)$ & $0(0.0)$ & & \\
\hline $\begin{array}{l}\text { Needs for care on paid employment } \\
\quad \text { (CANSAS item 23) }\end{array}$ & & & & & & 63.469 & $0.00 *$ \\
\hline No needs & 704 (65.9) & 427 (93.9) & $36(15.7)$ & $111(49.6)$ & $130(81.3)$ & & \\
\hline Met needs & $214(20.0)$ & $2(0.4)$ & $167(72.6)$ & $24(10.7)$ & $21(13.1)$ & & \\
\hline Unmet needs & $151(14.1)$ & $26(5.7)$ & $27(11.7)$ & $89(39.7)$ & $9(5.6)$ & & \\
\hline Gender & & & & & & 2.914 & 0.41 \\
\hline Male & $700(65.5)$ & $292(64.2)$ & $148(64.3)$ & $144(64.3)$ & $116(72.5)$ & & \\
\hline Female & $369(34.5)$ & $163(35.8)$ & $82(35.7)$ & $80(35.7)$ & $44(27.5)$ & & \\
\hline Living situation & & & & & & 11.293 & $0.01 *$ \\
\hline Independent $^{\mathrm{a}}$ & $848(79.3)$ & $355(78.0)$ & $169(73.5)$ & $178(79.5)$ & $146(91.3)$ & & \\
\hline Dependent & $221(20.7)$ & $100(22.0)$ & $61(26.5)$ & $46(20.5)$ & $14(8.7)$ & & \\
\hline Educational level $^{\mathrm{b}}$ & & & & & & 35.007 & $0.00 *$ \\
\hline Low $^{\mathrm{c}}$ & $451(42.2)$ & $210(46.2)$ & $77(33.5)$ & $119(53.1)$ & $45(28.1)$ & & \\
\hline Medium $^{\mathrm{d}}$ & $374(35.0)$ & $159(34.9)$ & $95(41.3)$ & $71(31.7)$ & $49(30.6)$ & & \\
\hline $\mathrm{High}^{\mathrm{e}}$ & $244(22.8)$ & $86(18.9)$ & $58(25.2)$ & $34(15.2)$ & $66(41.3)$ & & \\
\hline Clinical diagnosis & & & & & & 1.107 & 0.78 \\
\hline Psychotic disorder & $821(76.8)$ & $352(77.4)$ & $169(73.5)$ & $175(78.1)$ & $125(78.1)$ & & \\
\hline Other disorder & $248(23.2)$ & 103 (22.6) & $61(26.5)$ & 49 (21.9) & $35(21.9)$ & & \\
\hline Having a life partner & & & & & & 8.683 & $0.03 *$ \\
\hline Yes & $320(29.9)$ & $123(27.0)$ & $56(24.3)$ & $79(35.3)$ & $62(38.8)$ & & \\
\hline No & $749(70.1)$ & $332(73.0)$ & $174(75.7)$ & $145(64.7)$ & $98(61.2)$ & & \\
\hline $\begin{array}{l}\text { Needs for care on social contacts } \\
\quad(\text { CANSAS item 14) }\end{array}$ & & & & & & 112.620 & $0.00 *$ \\
\hline No needs & $683(63.9)$ & $339(74.5)$ & $136(59.1)$ & $73(32.6)$ & $135(84.4)$ & & \\
\hline Met needs & $163(15.2)$ & $62(13.6)$ & $61(26.5)$ & $23(10.3)$ & $17(10.6)$ & & \\
\hline \multirow[t]{2}{*}{ Unmet needs } & $223(20.9)$ & $54(11.9)$ & $33(14.4)$ & $128(57.1)$ & $8(5.0)$ & & \\
\hline & $M(\mathrm{SE})$ & $M(\mathrm{SE})$ & $M(\mathrm{SE})$ & $M(\mathrm{SE})$ & $M(\mathrm{SE})$ & & \\
\hline Age (years) & $44.06(0.33)$ & $48.17(0.56)$ & $40.89(0.76)$ & $43.64(0.88)$ & $43.54(0.83)$ & 60.740 & $0.00 *$ \\
\hline Duration in MHC (in years) & $16.57(0.37)$ & $19.71(0.60)$ & $15.51(0.88)$ & $15.55(1.00)$ & $15.52(0.93)$ & 23.970 & $0.00 *$ \\
\hline QOL (MANSA total) & $58.06(0.38)$ & $60.82(0.64)$ & $58.32(0.80)$ & $48.33(1.11)$ & $64.75(0.86)$ & 136.310 & $0.00 *$ \\
\hline $\begin{array}{l}\text { Psychosocial functioning (HoNOS } \\
\text { total) }\end{array}$ & $7.15(0.16)$ & $7.70(0.28)$ & $6.67(0.35)$ & $9.69(0.45)$ & $4.56(0.37)$ & 83.806 & $0.00 *$ \\
\hline $\begin{array}{l}\text { Psychiatric symptoms (HoNOS } \\
\text { symptoms) }\end{array}$ & $2.82(0.08)$ & $2.75(0.13)$ & $2.85(0.17)$ & $3.73(0.22)$ & $1.96(0.18)$ & 38.154 & $0.00 *$ \\
\hline
\end{tabular}

*significant at 0.05

${ }^{\text {a }}$ Sheltered accommodation or hospitalized

${ }^{\mathrm{b}}$ Ref. [71] 
Table 2 (continued)

${ }^{\mathrm{C} I S C E D}$ levels 0,1 and 2

${ }^{\mathrm{d}}$ ISCED levels 3, 4 and 5

${ }^{\text {e} I S C E D ~ l e v e l s ~} 6$ and 7

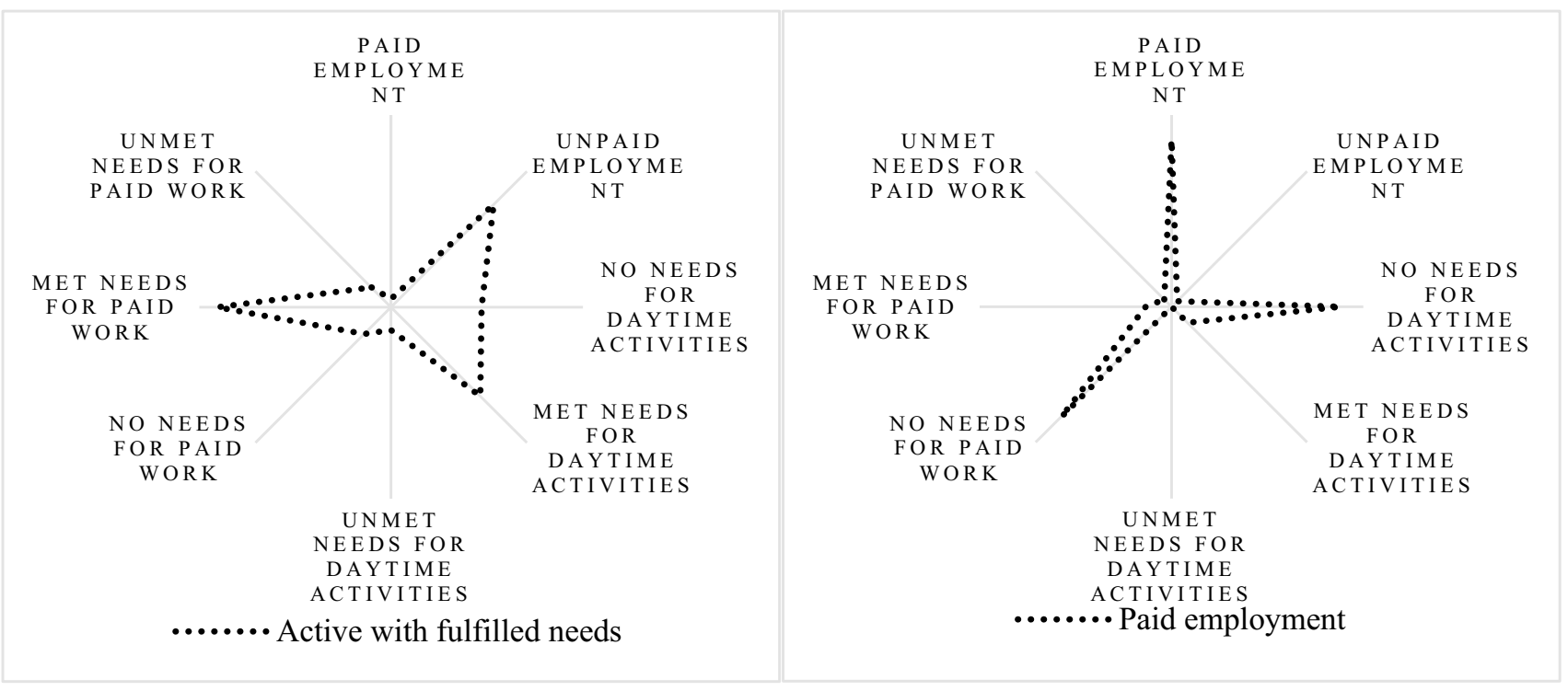

\begin{tabular}{|c|c|}
\hline \multicolumn{2}{|c|}{$\begin{array}{l}\text { PAID } \\
\text { EMPLOYME } \\
\text { NT }\end{array}$} \\
\hline $\begin{array}{c}\text { UNMET } \\
\text { NEEDS FOR } \\
\text { PAID WORK }\end{array}$ & $\begin{array}{c}\text { UNPAID } \\
\text { EMPLOYME } \\
\text { NT }\end{array}$ \\
\hline $\begin{array}{l}\text { MET NEEDS } \\
\text { FOR PAID } \\
\text { WORK }\end{array}$ & $\begin{array}{c}\text { NO NEEDS } \\
\text { FOR } \\
\text { DAYTIME } \\
\text { ACTIVITIES }\end{array}$ \\
\hline $\begin{array}{l}\text { NO NEEDS } \\
\text { FOR PAID } \\
\text { WORK }\end{array}$ & $\begin{array}{c}\text { MET NEEDS } \\
\text { FOR } \\
\text { DAYTIME } \\
\text { ACTIVITIES }\end{array}$ \\
\hline & \\
\hline$\cdots$ & ctive \\
\hline
\end{tabular}

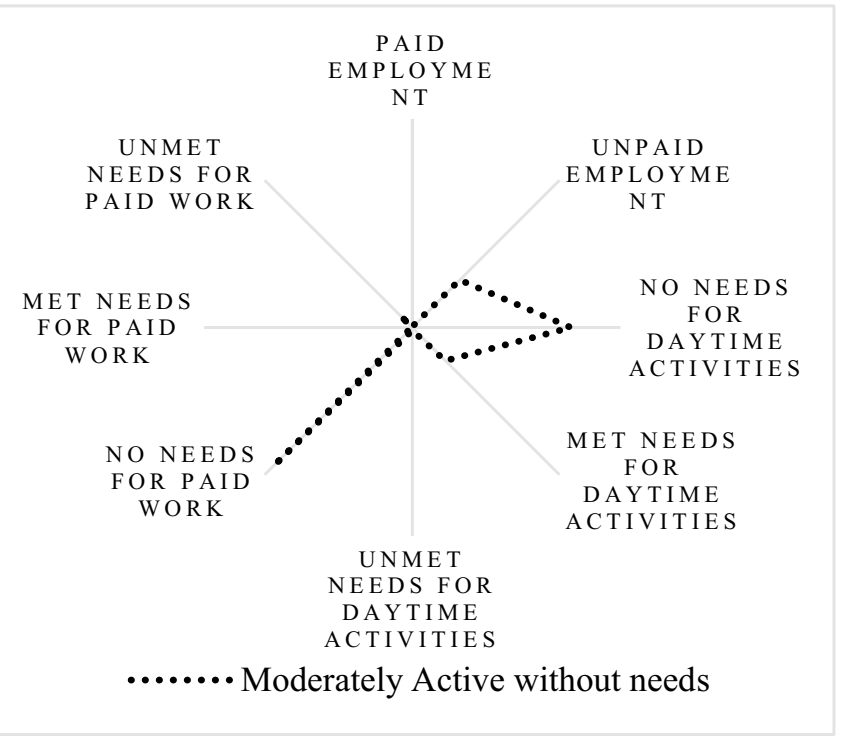

Fig. 1 Latent class profiles

to these classes regarding independent living, with most members living independently.

Members of class 4, paid employment, were higher educated than the other classes (41.4\% high educational level) and had the best psychosocial functioning and fewest psychiatric symptoms. Furthermore, they had fewer needs for care regarding social contacts, the highest QOL and most independent living members of all classes.

\section{Vignettes}

To better understand differences between participation classes, fictional vignettes were created by the researchers for each, based on differences found. 


\section{Moderately active without needs}

Bob is a 50-year-old man with schizophrenia who has been in psychiatric care for more than 30 years, but is not experiencing symptoms at this moment. Bob quit school after 10th grade and has no working experience. Bob, who lives alone, spent his days watching television and taking care of his cat. Bob sometimes wishes he had more friends. However, for the most part, Bob is content with his quiet life and has no need for other daytime activities or paid work. He previously used to visit a day activity center, but has stopped doing so since its relocation.

\section{Active with fulfilled needs}

Susan is a 37-year-old woman who lives in a sheltered housing facility. She is a high school graduate who had her first psychotic episode 12 years ago and over time experienced psychiatric symptoms in varying degrees. She likes being a coffee host in a neighborhood center, where she has made many friends. Her case manager was supportive when she expressed a wish for more daytime activities and helped her get this volunteer job. They briefly considered getting a paid job, but decided that she was too unstable. Overall, she is content with life, but believes life would be better if she had a boyfriend and a place to live on her own.

\section{Involuntarily inactive}

Fred is a 44-year-old man with schizophrenia who has experienced many symptoms for over 16 years and lives with his girlfriend. Fred dropped out of school early and now fills his time with watching television and sleeping. He is bored and eager to do more, but he does not know what. His neighbor sometimes makes suggestions, but otherwise, Fred receives no help with activities. The sessions with his case manager and psychiatrist are primarily focused on symptoms. Fred is very unhappy with the fact that he has nothing to do and no social contacts besides his partner and neighbor.

\section{Paid employment}

Jill is a 42-year-old woman who lives with her husband. She was diagnosed with schizophrenia after two episodes 15 and 12 years ago. Occasionally, she has symptoms, but with adequate medication, she can prevent them from interfering much with daily life. After graduation, Jill started working at a bank. After two episodes, she found a part-time job and currently works as a manager. Her job, husband, and other social contacts keep Jill well-occupied and she has no wish for other activities. Although she would like to be free of psychiatric medication, Jill is happy with her life and considers herself lucky being able to work.

\section{Discussion}

Social participation, here defined as having paid employment or other daytime activities, is highly valued [72, 73], promotes QOL, and as such, is a key aspect of recovery [14]. This study aimed to investigate which factors are related to the level of social participation of individuals with SMI by identifying subgroups based on needs for care in this area and actual participation. Four subgroups were identified that differ significantly in socio-demographics, QOL, psychosocial functioning, and psychiatric symptoms.

The subgroup that was most actively engaged in paid employment can be described as high-functioning, not only in terms of social participation, but members also had the fewest psychiatric symptoms, best psychosocial functioning, and highest educational level overall. Possibly as a result, they expressed the highest QOL and mostly no needs for more social contacts or support regarding paid work or other daytime activities. Rehabilitation support for this subgroup should focus on keeping a stable employment situation-while keeping an open mind for career opportunities-and dealing with possible problems caused by psychiatric symptoms [74].

At the other end of the spectrum was the subgroup involuntarily inactive with individuals with almost no paid or unpaid employment but an alarmingly high percentage of unmet needs for care regarding social contacts, daytime activities, and paid employment. This seems to be a particularly vulnerable group and special attention should be given to better facilitate them, as this is also the subgroup with the most problems in psychosocial functioning, many psychiatric symptoms, and low QOL.

The third subgroup (active with fulfilled needs) had high percentages of members active in voluntary work with mostly met needs, suggesting that they have benefitted most from vocational rehabilitation. Compared to the others, they are younger with relatively good psychosocial functioning, but more often hospitalized or in sheltered accommodation. Albeit less obvious than the involuntarily inactive consumers, this subgroup contains individuals in need of special attention because of unmet needs for care regarding paid employment. These individuals, and to a lesser extent, all members of this group are at risk of settling for unpaid work while paid work could be a realistic option considering their age and psychosocial functioning. To prevent widening the gap with the labor market whilst working on recovery, it is important to keep discussing needs for support regarding paid work and to avoid losing hope and aspiration, which can be a consequence of coping with severe mental illnesses. Since a core task of supported and sheltered housing is supporting inhabitants 
with daytime activities, the high percentage of met needs for care in this subgroup could be related to their specific living environment rather than a characteristic of the individuals themselves $[75,76]$.

Finally, the subgroup moderately active without needs can be characterized as older, stable in a chronic phase of the illness and with few needs for care in the social and vocational domain. Strikingly, this 'silent majority' has relatively few psychiatric symptoms and the second highest QOL. On the other hand, they have the second poorest psychosocial functioning and a low educational level. Social participation in this subgroup may be restricted more by problems in psychosocial functioning than by symptom severity, which makes it interesting to further investigate why some individuals in this group do find satisfactory daytime activities, whereas others do not.

These four different subgroups, particularly the highfunctioning group and the older chronic group with few needs for care, have been identified in earlier research [77-80]. Hannah [80] found that high-functioning chronic patients score high on social interaction, a dimension that in this study comprises meaningful activities. Hannah's mainstream chronically mentally ill cluster is comparable to the moderately active without needs individuals with their lack of extreme features (except age), relatively low level of psychiatric symptoms and few activities.

Although Hannah's and our results suggest a continuum ranging from worse symptoms and less participation to few symptoms and more participation, the middle two subgroups do not follow this order and show that this is an oversimplification of reality. For instance, one would expect the worst functioning subgroup to be the most hospitalized but that is not the case, nor were there differences in clinical diagnosis, duration in MHC, having a life partner or age. This differs from a study by Lloyd-Evans [86], who found that those in competitive employment were typically younger. However, their finding that high educational level was related to employment was corroborated by our study. Whereas some earlier studies found that male gender was related to better employment outcomes [22], our study confirms others who showed this gender effect to be rather ambiguous [46]. The lack of a significant difference for diagnosis, expressed as having a psychotic disorder or not, implies that social participation is more related to symptoms than to diagnostic labels and confirms results from others [46].

An important conclusion of our study is that a fair number of individuals with SMI do not receive support in line with their needs $(17 \%$ unmet needs for care regarding daytime activities, $14 \%$ unmet needs for care for paid work, and $21 \%$ for social contacts). The participating FACT teams in our study used external employment specialists whereas Kortrijk et al. [74] stress the importance of integrating specialized employment services according to the model of individual placement and support [81, 82] in FACT teams, and show that employment needs are otherwise rarely addressed. Occupational therapists could also play a valuable role in attaining other daytime activities besides paid work [83].

A major limitation of this study is that data were not specifically gathered for these research questions and that detailed information about the level of social participation was lacking. In addition, the fact that all participants come from one region in the middle of The Netherlands could be seen as a limitation. Results may not be generalizable to areas with higher unemployment rates or with other opportunities to engage in employment and other daytime activities. However, this is mitigated by the large, representative sample size, its heterogeneity in terms of backgrounds, and the fact that the participating FACT teams were located in the center of a larger city but also in smaller surrounding towns.

Another drawback is that the sample may be a biased selection of relatively well-functioning patients who were able and willing to engage in routine outcome assessments, leaving out those with severe psychotic symptoms and limitations in functioning that prevent them from participating [84]. However, it is also possible that the worst as well as the best functioning individuals are underrepresented because of higher non-response in those who are doing well and distance themselves from mental health care.

A final limitation is the cross-sectional design that did not allow a dynamic and/or causal view on the factors associated with social participation. For instance, it is not clear whether the active with fulfilled needs and paid employment subgroups are engaged in work because their psychosocial functioning is good or whether this results from remaining active [74]. As Morgan et al. [85] put it, persisting poor mental health may be a cause but also a consequence of social exclusion and poverty. More longitudinal research is needed to clarify this relationship.

Strong points of this study are the large sample size, and the focus on unpaid vocational activities, which are mostly overlooked in the literature [86]. Furthermore, not only the actual level of social participation was taken into account, but also needs for care and support in this area. This distinction is important, because there seems to be a gap between an expressed desire to work and actual job-seeking behavior [36].

The study results are clinically relevant, because subgroups based on routinely measured outcomes can help clinicians identify which of their clients need more support with finding jobs or activities. Special attention in this regard should be given to involuntarily inactive individuals as well as individuals seemingly satisfied with unpaid work but who could experience a lack of support when trying to find paid employment.

The fact that the unemployment rates of individuals with SMI have been fairly constant over the past 25 years 
$[15,36,87,88]$ despite increasing implementation of psychiatric rehabilitation indicates that there is a strong urge for new knowledge about predictors of social participation. The next step in this line of research would be to conduct growth analyses and make dynamic models to see whether individuals with SMI change subgroups over time.

More qualitative approaches, elucidating the complex interplay between positive and negative consequences associated with employment-related activities [89], could further increase understanding of why some people with SMI are engaged in social participation, while others are not. Next, it would also be valuable to have research focus on contextual barriers and facilitators that influence social participation. After all, participation is a reciprocal process, which means that where individuals with SMI want to participate in society, society also has the obligation and responsibility to let them in.

\section{Compliance with ethical standards}

Conflict of interest The authors declare that there are no conflicts of interest.

Ethical standards Informed consent was obtained from all participants prior to data collection. Study protocol and informed consent form were approved by the Ethical review board of Altrecht Science (\#1724). The study has been performed in accordance with the ethical standards laid down in the 1964 Declaration of Helsinki and its later amendments.

Open Access This article is distributed under the terms of the Creative Commons Attribution 4.0 International License (http://creativeco mmons.org/licenses/by/4.0/), which permits unrestricted use, distribution, and reproduction in any medium, provided you give appropriate credit to the original author(s) and the source, provide a link to the Creative Commons license, and indicate if changes were made.

\section{References}

1. Burns-Lynch B, Brusilovskiy E, Salzer MS (2016) An empirical study of the relationship between community participation, recovery, and quality of life of individuals with serious mental illnesses. Isr J Psychiatry 53(1):46-55

2. Arns PG, Linney JA (1993) Work, self, and life satisfaction for persons with severe and persistent mental disorders. Psychosoc Rehabil J 17(2):63

3. Bell MD, Lysaker PH, Milstein RM (1996) Clinical benefits of paid work activity in schizophrenia. Schizophr Bull 22(1):51

4. Dunn EC, Wewiorski NJ, Rogers ES (2008) The meaning and importance of employment to people in recovery from serious mental illness: results of a qualitative study. Psychiatr Rehabil J 32(1):59

5. Priebe S, Warner R, Hubschmid T, Eckle I (1998) Employment, attitudes toward work, and quality of life among people with schizophrenia in three countries. Schizophr Bull 24(3):469-477

6. Eklund M, Hansson L, Ahlqvist C (2004) The importance of work as compared to other forms of daily occupations for wellbeing and functioning among persons with long-term mental illness. Community Ment Health J 40(5):465-477

7. Marwaha S, Johnson S, Bebbington P, Angermeyer MC, Brugha T, Azorin J-M, Kilian R, Kornfeld A, Toumi M, Group ES (2008) Correlates of subjective quality of life in people with schizophrenia: findings from the EuroSC study. J Nerv Ment Dis 196(2):87-94

8. Eklund M (2009) Work status, daily activities and quality of life among people with severe mental illness. Qual Life Res 18(2):163-170

9. Leufstadius C, Eklund M (2008) Time use among individuals with persistent mental illness: identifying risk factors for imbalance in daily activities. Scand J Occup Ther 15(1):23-33

10. Provencher HL, Gregg R, Mead S, Mueser KT (2002) The role of work in the recovery of persons with psychiatric disabilities. Psychiatr Rehabil J 26(2):132

11. Strong S (1998) Meaningful work in supportive environments: experiences with the recovery process. Am J Occup Ther 52(1):31-38

12. Lloyd C, King R, Moore L (2010) Subjective and objective indicators of recovery in severe mental illness: a cross-sectional study. Int J Soc Psychiatry 56(3):220-229

13. Huxley P, Thornicroft G (2003) Social inclusion, social quality and mental illness. Br J Psychiatry 182(4):289-290

14. McGurk SR, Mueser KT, DeRosa TJ, Wolfe R (2009) Work, recovery, and comorbidity in schizophrenia: a randomized controlled trial of cognitive remediation. Schizophr Bull 35(2):319-335

15. Drake RE, Whitley R (2014) Recovery and severe mental illness: description and analysis. Can J Psychiatry 59(5):236-242

16. Mueser KT, Salyers MP, Mueser PR (2001) A prospective analysis of work in schizophrenia. Schizophr Bull 27(2):281-296

17. Rogers E, Walsh D, Masotta L, Danley K (1991) Massachusetts survey of client preferences for community support services (final report). Center for Psychiatric Rehabilitation, Boston

18. Holley HL, Hodges P, Jeffers B (1998) Moving psychiatric patients from hospital to community: views of patients, providers, and families. Psychiatr Serv 49(4):513-517

19. Seebohm P, Secker J (2005) What do service users want. In: Grove B, Secker J, Seebohm P (ed) New Thinking About Mental Health Employment. Radcliffe Publishing, Oxford, Seattle, p $11-18$

20. Swildens W, van Busschbach JT, Michon H, Kroon H, Koeter MW, Wiersma D, van Os J (2011) Effectively working on rehabilitation goals: 24-month outcome of a randomized controlled trial of the Boston psychiatric rehabilitation approach. Can J Psychiatry Revue canadienne de psychiatrie 56(12):751-760

21. Marwaha S, Johnson S, Bebbington P, Stafford M, Angermeyer MC, Brugha T, Azorin J-M, Kilian R, Hansen K, Toumi M (2007) Rates and correlates of employment in people with schizophrenia in the UK, France and Germany. Br J Psychiatry 191(1):30-37

22. Salkever DS, Karakus MC, Slade EP, Harding CM, Hough RL, Rosenheck RA, Swartz MS, Barrio C, Yamada AM (2007) Measures and predictors of community-based employment and earnings of persons with schizophrenia in a multisite study. Psychiatr Serv 58(3):315-324

23. Cook JA (2006) Employment barriers for persons with psychiatric disabilities: a report for the President's New Freedom Commission. Psychiatr Serv 57(10):1391-1405

24. Statistics Netherlands (CBS) (2017) Sustained decline unemployment. https://www.cbs.nl/en-gb/news/2017/16/sustaineddecline-unemployment. Accessed 2017

25. Bureau of Labor Statistics (2017) Labor force statistics from the current population survey (Dataset). https://data.bls.gov/times eries/LNS14000000. Accessed 2017 
26. Office for National Statistics (2017) Unemployment rate (Dataset). https://www.ons.gov.uk/employmentandlabourmarket/ peoplenotinwork/unemployment. Accessed 2017

27. Shimitras L, Fossey E, Harvey C (2003) Time use of people living with schizophrenia in a North London catchment area. Br J Occup Ther 66(2):46-54

28. Minato M, Zemke R (2004) Time use of people with schizophrenia living in the community. Occup Ther Int 11(3):177-191

29. Hayes RL, Halford WK (1996) Time use of unemployed and employed single male schizophrenia subjects. Schizophr Bull 22(4):659-669

30. Bejerholm U, Eklund M (2004) Time use and occupational performance among persons with schizophrenia. Occup Ther Ment Health 20(1):27-47

31. Crist PH, Davis CG, Coffin PS (2000) The effects of employment and mental health status on the balance of work, play/leisure, selfcare, and rest. Occup Ther Ment Health 15(1):27-42

32. Gard DE, Sanchez AH, Cooper K, Fisher M, Garrett C, Vinogradov S (2014) Do people with schizophrenia have difficulty anticipating pleasure, engaging in effortful behavior, or both? J Abnorm Psychol 123(4):771

33. Farnworth L (2000) Time use and leisure occupations of young offenders. Am J Occup Ther 54(3):315-325

34. Passmore A (1998) Does leisure support and underpin adolescents' developing worker role? J Occup Sci 5(3):161-165

35. Brown S, Birtwistle J, Roe L, Thompson C (1999) The unhealthy lifestyle of people with schizophrenia. Psychol Med 29(3):697-701

36. Marwaha S, Johnson S (2004) Schizophrenia and employment. Soc Psychiatry Psychiatr Epidemiol 39(5):337-349

37. Rüsch N, Angermeyer MC, Corrigan PW (2005) Mental illness stigma: concepts, consequences, and initiatives to reduce stigma. Eur Psychiatry 20(8):529-539

38. Schulze B, Angermeyer MC (2003) Subjective experiences of stigma. A focus group study of schizophrenic patients, their relatives and mental health professionals. Soc Sci Med 56(2):299-312

39. McGurk SR, Mueser KT, Pascaris A (2005) Cognitive training and supported employment for persons with severe mental illness: one-year results from a randomized controlled trial. Schizophr Bull 31(4):898-909

40. Corrigan PW, Larson JE, Ruesch N (2009) Self-stigma and the "why try" effect: impact on life goals and evidence-based practices. World Psychiatry 8(2):75-81

41. Thornicroft G, Brohan E, Rose D, Sartorius N, Leese M, Group IS (2009) Global pattern of experienced and anticipated discrimination against people with schizophrenia: a cross-sectional survey. Lancet 373(9661):408-415

42. Drake RE, Essock SM (2009) The science-to-service gap in realworld schizophrenia treatment: the $95 \%$ problem. Schizophr Bull 35(4):677-678

43. Wiersma D (2006) Needs of people with severe mental illness. Acta Psychiatr Scand 113(s429):115-119

44. Phelan M, Slade M, Thornicroft G, Dunn G, Holloway F, Wykes T, Strathdee G, Loftus L, McCrone P, Hayward P (1995) The Camberwell assessment of need: the validity and reliability of an instrument to assess the needs of people with severe mental illness. Br J Psychiatry 167(5):589-595

45. Slade M, Phelan M, Thornicroft G (1998) A comparison of needs assessed by staff and by an epidemiologically representative sample of patients with psychosis. Psychol Med 28(3):543-550

46. Wewiorski NJ, Fabian ES (2004) Association between demographic and diagnostic factors and employment outcomes for people with psychiatric disabilities: a synthesis of recent research. Ment Health Serv Res 6(1):9-21
47. Michon HW, van Weeghel J, Kroon H, Smit F, Schene AH (2006) Predictors of successful job finding in psychiatric vocational rehabilitation: an expert panel study. J Vocat Rehabil 25(3):161-171

48. Kirsh B (2000) Work, workers, and workplaces: a qualitative analysis of narratives of mental health consumers. J Rehabil 66(4):24

49. De Beurs ED, den Hollander-Gijsman ME, van Rood YR, Van der Wee NJ, Giltay EJ, van Noorden MS, van der Lem R, van Fenema E, Zitman FG (2011) Routine outcome monitoring in the Netherlands: practical experiences with a web-based strategy for the assessment of treatment outcome in clinical practice. Clin Psychol Psychother 18(1):1-12

50. Parabiaghi A, Kortrijk HE, Mulder CL (2014) Defining multiple criteria for meaningful outcome in routine outcome measurement using the Health of the Nation Outcome Scales. Soc Psychiatry Psychiatr Epidemiol 49(2):291-305

51. Mulder C, van der Gaag M, Bruggeman R, Cahn W, Delespaul P, Dries P, Faber G, de Haan L, van der Heijden F, Kempen R (2010) Routine outcome monitoring for patients with severe mental illness: a consensus document. Tijdschrift voor psychiatrie 52(3):169-179

52. Eisen SV, Ranganathan G, Seal P, Spiro A (2007) Measuring clinically meaningful change following mental health treatment. J Behav Health Serv Res 34(3):272-289

53. van Veldhuizen JR (2007) FACT: a Dutch version of ACT. Community Ment Health J 43(4):421-433

54. Bond GR, Drake RE, Mueser KT, Latimer E (2001) Assertive community treatment for people with severe mental illness. Dis Manag Health Outcomes 9(3):141-159

55. Van Veldhuizen JR, Bähler M (2013) Manual flexible ACT Manual Flexible ACT Vision, model, practice and organization. Groningen

56. Nugter MA, Engelsbel F, Bähler M, Keet R, van Veldhuizen R (2016) Outcomes of FLEXIBLE assertive community treatment (FACT) implementation: a prospective real life study. Community Ment Health J 52(8):898-907

57. (NIMH) NIoMH (1987) Toward a model plan for a comprehensive. Community-based Mental Health System, Washington DC

58. Slade M (2002) What outcomes to measure in routine mental health services, and how to assess them: a systematic review. Aust N Z J Psychiatry 36(6):743-753

59. Slade M, Beck A, Bindman J, Thornicroft G, Wright S (1999) Routine clinical outcome measures for patients with severe mental illness: CANSAS and HoNOS. Br J Psychiatry 174(5):404-408

60. Drukker M, Bak M, à Campo J, Driessen G, Van Os J, Delespaul P (2010) The cumulative needs for care monitor: a unique monitoring system in the south of the Netherlands. Soc Psychiatry Psychiatr Epidemiol 45(4):475-485

61. Andresen R, Caputi P, Oades LG (2000) Interrater reliability of the Camberwell assessment of need short appraisal schedule. Aust N Z J Psychiatry 34(5):856-861

62. Priebe S, Huxley P, Knight S, Evans S (1999) Application and results of the manchester short assessment of quality of life (MANSA). Int J Soc Psychiatry 45(1):7-12

63. Van Nieuwenhuizen C, Schene AH, Koeter MWJ, Huxley PJ (2001) The Lancashire Quality of Life Profile: modification and psychometric evaluation. Soc Psychiatry Psychiatr Epidemiol 36(1):36-44

64. Björkman T, Svensson B (2005) Quality of life in people with severe mental illness. Reliability and validity of the manchester short assessment of quality of life (MANSA). Nordic J Psychiatry 59(4):302-306

65. Wing J, Beevor A, Curtis R, Park S, Hadden S, Burns A (1998) Health of the Nation Outcome Scales (HoNOS). Research and development. Br J Psychiatry 172(1):11-18 
66. Vermunt JK, Magidson J (2002) Latent class cluster analysis. In: Hagenaars J, McCutcheon A (eds) Applied Latent Class analysis. Cambridge University Press, Cambridge, pp 89-106

67. Vermunt JK, Magidson J (2005) Latent GOLD 4.0 user's guide. Statistical Innovations Inc., Belmont

68. Vermunt JK, Magidson J (2013) Latent GOLD 5.0 upgrade manual. Statistical Innovations Inc, Belmont

69. Bozdogan H (1993) Choosing the number of component clusters in the mixture-model using a new informational complexity criterion of the inverse-Fisher information matrix. In: Information and classification. Springer, New York, pp 40-54

70. Lanza ST, Rhoades BL (2013) Latent class analysis: an alternative perspective on subgroup analysis in prevention and treatment. Prev Sci 14(2):157-168

71. OECD, European Union, UNESCO Institute for Statistics (2015) ISCED 2011 operational manual: guidelines for classifying national education programmes and related qualifications. OECD Publishing

72. Hvalsøe B, Josephsson S (2003) Characteristics of meaningful occupations from the perspective of mentally ill people. Scand J Occup Ther 10(2):61-71

73. Aubin G, Hachey R, Mercier C (1999) Meaning of daily activities and subjective quality of life in people with severe mental illness. Scand J Occup Ther 6(2):53-62

74. Kortrijk HE, Mulder NL, Kamperman AM, van Weeghel J (2018) Employment rates in flexible assertive community treatment teams in the Netherlands: an observational study. Community Ment Health J 55(2):350-359

75. Nelson G, Laurier W (2010) Housing for people with serious mental illness: approaches, evidence, and transformative change. J Soc Soc Welf 37:123

76. de Heer-Wunderink C, Visser E, Caro-Nienhuis A, Sytema S, Wiersma D (2012) Supported housing and supported independent living in the Netherlands, with a comparison with England. Community Ment Health J 48(3):321-327

77. Sheets JL, Prevost JA, Reihman J (1982) Young adult chronic patients: three hypothesized subgroups. Psychiatr Serv 33(3):197-203

78. Harris M, Bergman HC, Bachrach LL (1986) Individualized network planning for chronic psychiatric patients. Psychiatr Q $58(1): 51-56$
79. Hazel KL, Herman SE, Mowbray CT (1991) Characteristics of seriously mentally ill adults in a public mental health system. Psychiatr Serv 42(5):518-525

80. Hannah MT (1993) An empirical typology of seriously and persistently mentally ill patients using symptom and social functioning factors. J Clin Psychol 49(5):622-637

81. Michon H, van Busschbach JT, Stant AD, van Vugt MD, van Weeghel J, Kroon H (2014) Effectiveness of individual placement and support for people with severe mental illness in the Netherlands: a 30-month randomized controlled trial. Psychiatr Rehabil J 37(2):129

82. Drake RE, Becker DR (2013) IPS supported employment: an evidence-based approach. Oxford University Press, New York

83. Arbesman M, Logsdon DW (2011) Occupational therapy interventions for employment and education for adults with serious mental illness: a systematic review. Am J Occup Ther 65(3):238-246

84. Young AS, Grusky O, Jordan D, Belin TR (2000) Routine outcome monitoring in a public mental health system: the impact of patients who leave care. Psychiatr Serv 51(1):85-91

85. Morgan C, Burns T, Fitzpatrick R, Pinfold V, Priebe S (2007) Social exclusion and mental health. Br J Psychiatry 191(6):477-483

86. Lloyd-Evans B, Marwaha S, Burns T, Secker J, Latimer E, Blizard R, Killaspy H, Totman J, Tanskanen S, Johnson S (2013) The nature and correlates of paid and unpaid work among service users of London Community Mental Health Teams. Epidemiol Psychiatr Sci 22(2):169-180

87. Strauss JS, Breier A (1987) The Vermont longitudinal study of persons with severe mental illness, II: long-term outcome of subjects who retrospectively met DSM-III criteria for schizophrenia. Am J Psychiatry 144:727

88. Rutman ID (1994) How psychiatric disability expresses itself as a barrier to employment. Psychosoc Rehabil J 17(3):15

89. Honey A (2004) Benefits and drawbacks of employment: perspectives of people with mental illness. Qual Health Res 14(3):381-395 